\title{
ORGANOSILICON CHEMISTRY I: CYCLOPROPANATION BY CARBENE OR CARBENOID ADDITION TO AN ALLYLIC SILANE
}

\author{
E.O. Dare ${ }^{1 *}$ and Ling-Kang Liu ${ }^{2}$ \\ ${ }^{1}$ Department of Chemistry, University of Agriculture, P. O. Box 28, UNAAB Post office, \\ Abeokuta. Nigeria \\ ${ }^{2}$ Institute of Chemistry, Academia Sinica, Nankang, Taipei, Taiwan 11529, Republic of.China
}

(Received August 19, 2005; revised September 26, 2005)

\begin{abstract}
The syntheses of tetra(dichlorocyclopropane)silane 2 and tetra(cyclo- propane)silane 3 have been accomplished using dichlorocarbene $\left(\mathrm{CCl}_{2}\right)$ and carbenoid addition, respectively. Various phase transfer catalysts (PTC) have been tested for $: \mathrm{CCl}_{2}$ addition to tetraallylsilane 1. 2Benzilidine-N,N,N,N',N',N',-hexaethyl propane-1,3-diammonium dibromide (Dq-Br) was found to be effective in giving 2 in a yield above 80\%. A modified synthetic route to 3 by the reaction of 1 with $\mathrm{Zn}-\mathrm{Ag}$ couple and methylene iodide is also described. The success of the reaction has been attributed to an alternative work-up procedure.
\end{abstract}

KEY WORDS: Cyclopropanation; Phase transfer catalyst; Dichlorocarbene; Zn-Cu couple; Simmons-Smith reaction

\section{INTRODUCTION}

Considerable information is available on the synthesis of various kinds of cyclopropanes via carbene [1-4] or carbenoid [5-8] addition to olefins. However, only a few of these studies report carbene addition to unsaturated silanes, especially siloxanes. It has recently been reported that the reaction of dichlorocarbene with octavinylsilsesquioxane gives a polyhedral oligomeric species [9]. In the report, a procedure that prevented breaking of $\mathrm{Si}-\mathrm{O}$ or $\mathrm{Si}-\mathrm{C}$ during nucleophilic attack was adopted. The Simmons-Smith reaction [10] which involves reaction of alkene with a dihalogenomethane and zinc (usually in the presence of copper) is an alternative method for the formation of cylopropanes. This reaction, however, has limitations [11] and this has necessitated various modifications [12] to the Simmon-Smith reaction. Even though modifications have been reported, the mechanism of cyclopropanation is not altered by the changes.

No doubt, vinylic and allylic silicon compounds are versatile starting materials for its various derivatives. Notable among them is tetravinyl- and tetraallyl-silanes, which are excellent precursors to starburst dendritic polymers $[13,14]$. However, much has not been known of a successful cyclopropanation of allyllic silanes. In the earlier reported result using the usual work-up conditions, the readily formed cylopropane experienced a ring opening process [15]

Herein, report of the results of the cyclopropanation of tetraallysilane using carbene and carbenoid addition, is presented. In the report, an optimal reaction condition in catalytic environment for effective dichlorocyclopropanation had been established. Tetraallylsilane is considered as the main substrate because it has not been subjected to popular Simmons-Smith [10] nor Furukawa [16] cyclopropanation procedures.

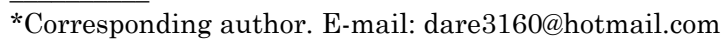




\section{RESULTS AND DISCUSSION}

Synthesis of $\mathrm{Dq}-\mathrm{Br}$

Starting from acetophenone, the synthesis of Diquat (Dq-Br), 2-benzilidine-N,N,N,N',N',N'hexaethyl propane-1,3-diammonium dibromide was achieved in a three step procedure as shown in Scheme 1.

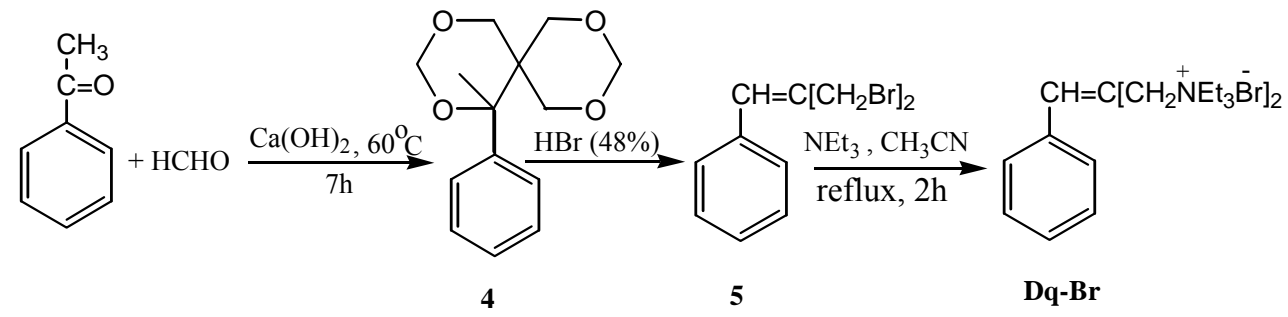

Scheme 1. Synthetic outline for Dq-Br.

The multi-site (catalyst with more than one active site) white solid Dq-Br, a quaternary ammonium salt was highly hygroscopic. Related multi-site phase transfer catalysts (PTC) have been synthesized in the literature [17-19] and used for various purposes [17, 18].

\section{Synthesis of tetra(dichlorocyclopropy)silane 2}

In the first instance, our continued interest in cyclopropane chemistry as well as recent advance in the cyclopropanation of octavinylsilsesquioxane [9] prompted an extension of the same ideal to tetraallylsilane, a substrate mostly used in the literature $[13,14]$ as precursor to dendritic polymers. In this work, we have successfully demonstrated the utilities of various PTCs: Dq-Br, tetrabutylammonium bromide (TBAB) and 18-crown-6 in the cyclopropanation of 1, usually in the presence of a base and chloroform. Following the synthetic Scheme 2, 2 was obtained in very good yield. In the presence of $\mathrm{Dq}-\mathrm{Br}$, TBAB and 18 -crown-6/KOH, 84\%, 79\% and $71 \%$ yields were observed respectively. There are several routes available for the generation of : $\mathrm{CX}_{2}$ which stress the necessity of operating under anhydrous condition, due to rapid hydrolysis of dihalocarbene. However, these difficulties are eliminated when the reactions are carried out in biphase systems using concentrated base and phase transfer catalyst [19-22].

Characterization of 2 using ${ }^{1} \mathrm{H}$ NMR, ${ }^{13} \mathrm{C}$ NMR, mass spectrometry and elemental analysis are satisfactory and agrees with the expected product, which was a yellowish-brown solid. Surprisingly, Dq-Br, a multi-site PTC was more productive than TBAB, a single-site PTC under the same reaction condition. Single-site PTCs have been proven as a near-optimal catalyst in organic PTC/OH${ }^{-}$systems. However, literature [16-18] reveals that the multi-site PTCs offer the potential of providing greater PTC activity and effect synthetic transformation under mild conditions. Hence, a better yield in the presence of water-soluble $\mathrm{Dq}-\mathrm{Br}$ compared to that catalyzed by 'single-site' PTC (TBAB) was found.

The dichlorocarbene addition reaction with 1 using crown ether to capture metal cation from the base system also afforded 2 whose quantitative formation is dependent on the ease at which metal cation form complex with crown ether (Table 1). The same trend was earlier reported [9]. However, yields were relatively appreciated in this case due to apparent absence of electronic hindrances in $\mathbf{1}$ compared to when octavinylsilsesquioxane [9] was the substrate. 
The first step of the : $\mathrm{CCl}_{2}$ addition mechanism is the removal of a proton from chloroform to produce the trichloromethide ion. In the second step trichloromethide ion loses chloride ion to give the neutral dichlorocarbene, which adds to allylic silane double bonds.

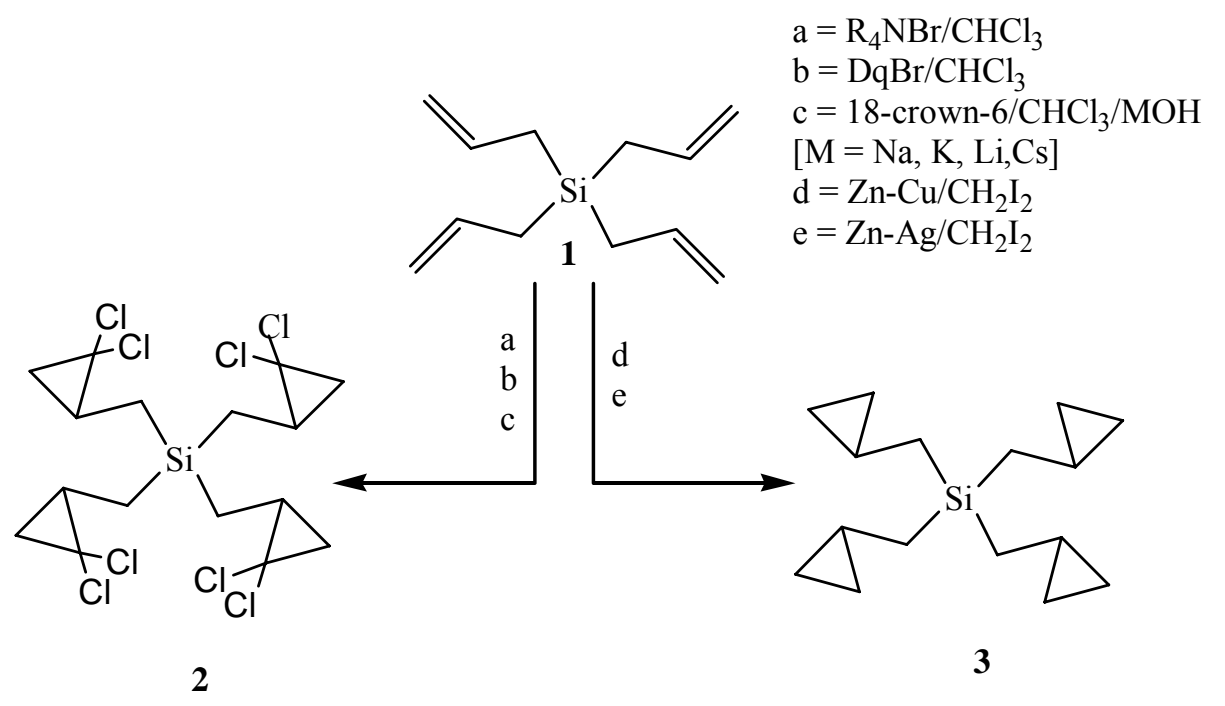

Scheme 2. Carbene and carbenoid addition to tetraallylsilane.

Table 1. Cyclopropanation using 18 -crown- $6 / \mathrm{CHCl}_{3}$ in the presence of various alkali.

\begin{tabular}{|l|l|}
\hline Alkali & Yield (\%) \\
\hline $\mathrm{KOH}$ & 71 \\
\hline $\mathrm{NaOH}$ & 62 \\
\hline $\mathrm{LiOH}$ & 43 \\
\hline $\mathrm{CsOH}$ & 67 \\
\hline
\end{tabular}

Synthesis of 3

A number of cyclopropanation reaction, which involves zinc carbenoid intermediate has been carried out in our laboratory. Most often, those reactions were aimed at improving capricious Simmons-Smith reactions and work-up. In this work, tatraallylsilane has been considered as substrate because it has not been involved in any of the Simmons-Smith reactions. Zinc-silver couple has been reported to be insufficiently reactive [23]; its use in the Simmons-Smith reaction has not been well investigated. In this report, cyclopropanation of 1 using $\mathrm{Zn}-\mathrm{Ag}$ couple and $\mathrm{CH}_{2} \mathrm{I}_{2}$ was achieved in a higher yield of 3 , and which proved advantageous over $\mathrm{Zn}-\mathrm{Cu}$ couple. Moreover, the reaction time was considerably reduced when $\mathrm{Zn}-\mathrm{Ag}$ couple was used. Further and ongoing experiments revealed that the improvement could be attributed to the presence of silver metal, which is only needed in a smaller amount compared with copper. It has been noted that while employing the conventional work-up conditions in the cyclopropanation of $\alpha, \beta$-unsaturated silyl ethers, the readily formed cyclopropanes undergone ring opening [15]. Moreover, the coordination complexes and some lewis acids are not always completely hydrolyzed using the usual work-up style. The remaining complexes, even when present in traces, may effect polymerization of the cyclopropane product. Consequently, effort was made to forestall such possible occurrence by adding pyridine to the ethereal solution instead of 
hydrolyzing the mixture. Under this procedure, 3 was conveniently isolated from side products like zinc complexes by repeated filtration. Interestingly, washing the filtrate with sodium thiosulphate as may be required in a conventional work-up is not necessary here because free iodine is not formed. Our successful attempt to transfer methylene from zinc carbenoid to the double bond of $\mathbf{1}$ also prompted an extension of the same reaction to octavinylsilsesquioxane [9]. Unfortunately, it was an unsuccessful reaction in this case. Presently, we are not able to give any explanation for the failure. The mechanism of the reaction might be related to that of the Simmon-Smith reaction but the synthetic procedure and work-up conditions are different and which gave 3 more easily. Spectroscopic techniques and elemental analysis have been used to characterize 3 ; the results are quite satisfactory.

\section{CONCLUSION}

Dq-Br among other PTCs used had proved to be the most effective and productive catalyst for the : $\mathrm{CCl}_{2}$ addition to tetraallylsilane. Furthermore, methylene transfer reaction in the presence of $\mathrm{Zn}-\mathrm{Ag}$ couple offers 3 in a relatively better yield and reduced time. The success of this methodology may be attributed to the silver metal surface and alternative work-up procedure adopted. The essential feature of the reaction is closely related to Simmons-Smith reaction.

\section{EXPERIMENTAL}

General. All reactions were carried out in an inert atmosphere unless otherwise noted. Commercial sources reagents (Aldrich and Fluka Chemicals) were used without further purification. $\mathrm{Zn}-\mathrm{Cu}$ couple was prepared according to a literature procedure [23].

IR spectra were recorded in $\mathrm{CH}_{2} \mathrm{Cl}_{2}$ unless otherwise stated, using $\mathrm{CaF}_{2}$ optic on a PerkinElmer 882 spectrophotometer. The ${ }^{1} \mathrm{H}$ NMR, ${ }^{13} \mathrm{C}$ NMR and ${ }^{29} \mathrm{Si}$ NMR were obtained on a Bruker AC 300 spectrometer. Chemical shifts are reported in $\delta$ values relative to the residual solvent resonance of $\mathrm{CDCl}_{3}\left({ }^{1} \mathrm{H}, \delta 7.24 ;{ }^{13} \mathrm{C}, \delta 77.0\right)$. Low resolution mass spectra were recorded on VG 70-250s mass spectrometer using FAB technique. Micro-analytical data were obtained with the use of a Perkin-Elmer 240C elemental analyzer.

\section{Synthesis of Diquat (Dq-Br)}

Compounds 4 and 5, precursors to Dq-Br were prepared following literature procedures [17-18]. $5(2.0 \mathrm{~g}, 0.010 \mathrm{M})$ was dissolved in dry acetonitrile $(20 \mathrm{~mL})$ and transferred into a $150 \mathrm{~mL}$ threenecked flask. To the solution was added $40 \mathrm{~mL}$ triethylamine. After the reaction mixture was refluxed for $2 \mathrm{~h}$ under nitrogen atmosphere, $30 \mathrm{~mL}$ diethyl ether was added to obtain a precipitate. After filtration and repeated washings with ether, a white solid was obtained and stored in a $\mathrm{CaCl}_{2}$-packed desiccator.

${ }^{1} \mathrm{H}$ NMR $\left(\mathrm{CDCl}_{3}\right) \delta: 1.58-1.2\left(\mathrm{~m}, 18 \mathrm{H},-\mathrm{CH}_{3}\right), 5.1-2.0\left(\mathrm{~m}, 16 \mathrm{H},-\mathrm{CH}_{2}\right), 8.0-7.1(\mathrm{~m}, 6 \mathrm{H}$, phenyl). ${ }^{13} \mathrm{C}$ NMR $\left(\mathrm{CDCl}_{3}\right) \delta: 154.87,133.35,128.98,128.77,128.18,118.93,55.89,52.66$, 52.33, 45.75, 7.8, 7.5. IR $\left(\mathrm{CH}_{2} \mathrm{Cl}_{2}, \mathrm{CaF}_{2}\right) v_{\max } \mathrm{cm}^{-1}: 3436,2632,2384,1648,1455,1020,759$.

\section{Preparation of Zn-Ag couple}

To a stirred hot solution of silver acetate $(10 \mathrm{mg})$ in acetic acid $(20 \mathrm{~mL})$, granular zinc $(1.7 \mathrm{~g}$, 0.026 g-atom) was added. The mixture was kept stirring for one minute, the zinc-silver couple 
formed was decanted and isolated and washed with acetic acid $(1 \times 20 \mathrm{~mL})$ and then ether $(5 \mathrm{x}$ $20 \mathrm{~mL})$. The couple was kept in a dry ether $(20 \mathrm{~mL})$ and covered with silver wool.

\section{Synthesis of 2}

Method A. A $100 \mathrm{~mL}$ flask was charged with $20 \mathrm{~mL}(40 \% \mathrm{w} / \mathrm{w}) \mathrm{NaOH}, 1.0 \mathrm{~mole} \%$ of Dq-Br or tetrabutylammonium bromide (TBAB) (the mole \% was based on 1), and chloroform $(50 \mathrm{~mL})$ was added. The reactants were conditioned for $10 \mathrm{~min}$ to maintain a temperature of $45{ }^{\circ} \mathrm{C} .1(1.0$ g, $5.2 \times 10^{-3}$ mole) was added to the reaction mixture and stirred for $8 \mathrm{~h}$ until the color of the reaction mixture changed to light yellow. To the cold reaction mixture, ether $(20 \mathrm{~mL})$ was added and the ethereal layer was washed with water and dried over anhydrous magnesium sulfate. The compounds were purified by column chromatography (alumina). Concentration on a rotatry evaporator gave a viscous yellow liquid, which under vacuum drying for $5 \mathrm{~h}$ gave a yellowishbrown solid 2. With Dq-Br PTC, the yield was $2.28 \mathrm{~g}$ (84\%) while TBAB gave $2.14 \mathrm{~g}$ (79\%).

${ }^{1} \mathrm{H}$ NMR $\left(\mathrm{CDCl}_{3}\right) \delta$ : 0.92-1.05 $\left(\mathrm{SiCH}_{2}-, \mathrm{m}, 2 \mathrm{H}\right) ; 1.23-1.26$ (-CH of dichlorocyclopropane, $\mathrm{m}$, $1 \mathrm{H})$; 1.56-1.68 $\left(-\mathrm{CH}_{2}\right.$ of dichlorocyclopropane, m, $\left.2 \mathrm{H}\right) ;{ }^{13} \mathrm{C} \mathrm{NMR}\left(\mathrm{CDCl}_{3}\right) \delta: 13.67\left(\mathrm{SiCH}_{2}\right)$, $26.66(-\mathrm{CH}-), 28.41\left(-\mathrm{CH}_{2}-\right), 62.16\left(\mathrm{CCl}_{2}\right) ;{ }^{29} \mathrm{Si} \mathrm{NMR}\left(\mathrm{CDCl}_{3}\right) \delta: 10.8(\mathrm{Si}) . \mathrm{IR}\left(\mathrm{CaF}_{2}, \mathrm{~cm}^{-1}\right)$ : $3154.8(\mathrm{C}-\mathrm{H}), 2955.9\left(\mathrm{CH}_{2}\right.$, cyclopropane), 1377.9 (Si-CH-),762 $\left(\mathrm{CCl}_{2}\right)$. MS (FAB): 523.84 $\left(\mathrm{M}^{+}\right.$, parent ion); elemental analysis calcd. for $\mathrm{C}_{16} \mathrm{H}_{20} \mathrm{Cl}_{8} \mathrm{Si}$ : C $35.4 \%, \mathrm{H} 3.62 \%$; found: $\mathrm{C}$ $36.98 \%$, H $3.75 \%$.

Method B. Chloroform (11.94 g, 0.10 mole) was added dropwise to a stirred mixture of 1 ( $1.0 \mathrm{~g}$, $5.2 \times 10^{-3}$ mole), powdered potassium hydroxide $(2.81 \mathrm{~g}, 0.05$ mole $)$ and 18 -crown-6 (1.0 mole $\%)$ in dichloromethane $(5.0 \mathrm{~mL})$ at $35^{\circ} \mathrm{C}$; the mixture was stirred at the same temperature for 12 $\mathrm{h}$ and extracted with ether, washed with water and dried over anhydrous magnesium sulfate. The compounds were purified by column chromatography (alumina). Concentration on a rotary evaporator gave a viscous yellow liquid, which under vacuum drying for $5 \mathrm{~h}$ gave a yellowishbrown solid 2 ( $71 \%$ yield). The same experimental procedure was repeated with the following alkalis: $\mathrm{NaOH}, \mathrm{CsOH}$, and $\mathrm{LiOH}$. The same analytical data as in method A was also obtained here.

\section{Synthesis of 3}

To an ethereal suspension of the zinc-silver couple, prepared as described above was added diiodomethane ( $3.4 \mathrm{~g}, 0.013$ mole) dropwise with stirring at such a rate to maintain gentle reflux. Stirring is continued for $1 \mathrm{~h}$ at room temperature. Then, 1 (1.92 g, 0.01 mole) was added dropwise over a period of $10 \mathrm{~min}$ and the mixture was refluxed for $5 \mathrm{~h}$. The mixture was then cooled to $0{ }^{\circ} \mathrm{C}$ (ice bath), and followed by dropwise addition of ether $(20 \mathrm{~mL})$ and pyridine $(1.26$ $\mathrm{g}, 0.016$ mole) over $1 \mathrm{~h}$ period. The resultant precipitate was removed by filtration and washed with ether $(3 \times 20 \mathrm{~mL})$. Filtrate and washings were combined and a little pyridine was added dropwise until no more precipitate was formed. After filtration, ether was evaporated in vacuo, the residual solution filtered, and the filtrate rectified in vacuo to give a white solid $(1.77 \mathrm{~g}$, $71 \%)$. Using a literature [23] procedure that utilizes acid hydrolysis worked-up, the yield was $1.27 \mathrm{~g}(53 \%)$.

${ }^{1} \mathrm{H}$ NMR $\left(\mathrm{CDCl}_{3}\right)$ \&: 0.46-0.57 $\left(\mathrm{SiCH}_{2^{-}}, \mathrm{m}, 2 \mathrm{H}\right) ; 0.34(-\mathrm{CH}<, \mathrm{m}, 1 \mathrm{H}) ; 0.20-0.31\left(-\mathrm{CH}_{2} \mathrm{CH}_{2-}\right.$, $\mathrm{m}, 4 \mathrm{H}) ;{ }^{13} \mathrm{C} \mathrm{NMR}\left(\mathrm{CDCl}_{3}\right) \delta: 2.50,4.1,8.4$ and $8.5 ;{ }^{29} \mathrm{Si} \mathrm{NMR}\left(\mathrm{CDCl}_{3}\right) \delta: 11.5(\mathrm{Si}) . \mathrm{IR}\left(\mathrm{CH}_{2} \mathrm{Cl}_{2}\right.$, $\left.\mathrm{CaF}_{2}\right) \mathrm{cm}^{-1}: 3048,3008,2969,1412,1244,1043$. MS (FAB): $248.31\left(\mathrm{M}^{+}\right.$, parent ion); elemental analysis calcd. for $\mathrm{C}_{16} \mathrm{H}_{28} \mathrm{Si}$ : C 77.41\%, H $11.28 \%$; found: C $77.98 \%, \mathrm{H} 11.36 \%$. 


\section{ACKNOWLEDGEMENTS}

The authors thank the National Science Council, Taiwan, ROC for the financial support. EOD gratefully acknowledge Dr C. Matsumae for running of some of the cyclopropane spectra in Japan. Department of Chemistry, UNAAB, Nigeria is gratefully acknowledged.

\section{REFERENCES}

1. Burke, S.D.; Grieco, P.A. Org. React. 1979, 26, 361.

2. Moss, R.A. Acc. Chem. Res. 1989, 22, 15.

3. Weber, W.P.; Gokel, G.W. Phase Transfer Catalysts in Orgarnic Synthesis, Springer Verlag: New York; 1977; p 2.

4. Rawson, R.J.; Harrison, I.T. J. Org. Chem. 1970, 35, 2057.

5. Brookhart, M.; Studabaker, W.B. Chem. Rev. 1987, 98, 911.

6. Doyle, M.P.; Forbes, D.C. Chem. Rev. 1998, 98, 911.

7. Galardon, E.; Mavx, P.L.; Simonneaux, G. Tetrahedron 2000, 56, 615.

8. Nishimura, J.; Furukawa, J.; Kawabata, N. J. Organomet. Chem. 1971, $29,237$.

9. Dare, E.O.; Olatunji, G.A.; Ogunniyi, D.S.; Lasisi, A.A. Polish J. Chem. 2005, 79, 109.

10. Simmons, H.E.; Smith, R.D. J. Am. Chem. Soc. 1958, 80, 5323; 1959, 81, 4256.

11. Conia, J.M.; Limasset, J.C. Tetrahedron Lett. 1965, 3151.

12. Fiedrich, E.C.; Demek, J.M.; Pong, R.Y. J. Org. Chem. 1985, 50, 4640.

13. Seyferth, D.; Son, D.Y. Organometallics 1994, 13, 2682.

14. Made, A.W.; Leevwen, P.W. J. Chem. Soc., Chem. Commun. 1992, 1400.

15. De Puy, C.H.; Breitbeil, F.W.; Debruin, K.R. J. Am. Chem. Soc.1966, 88, 3347.

16. Nishimura, J.; Furukawa, J.; Kawabata, N.; Fujita, T. Tetraheron 1970, 26, 2229.

17. Idoux, J.P.; Gupton, J.T. Multi-site Phase Transfer Catalysts in PTC, New Chemistry, Catalysts and Applications, Starks, C.M. (Ed.), ACS Symposium Series 326, Washington DC, 1987; Chap. 14, p 169.

18. Balakrishnan, T.; Paul, J. J. Synth. Commun. 1995, 25, 3821.

19. Balakrishnan, T.; Paul, J. J. Chem. Soc. Perkin Trans. 2 1995, 2081.

20. Abele, E.; Abele, R.; Lukevics, E. Heterocycl. Commun. 1998, 4, 253.

21. Dehmlow, E.V. Tetrahedron Lett. 1976, 91.

22. Rabinovitz, M.; Sasson, Y.; Halpern, M. J. Org. Chem. 1983, 48, 1022.

23. Goff, E.L. J. Org. Chem. 1964, 29, 2048. 